\title{
The protective role of quercetin and arginine on gold nanoparticles induced hepatotoxicity in rats
}

This article was published in the following Dove Press journal:

International Journal of Nanomedicine

\author{
Mohamed Anwar K \\ Abdelhalim' \\ Sherif A Abdelmottaleb \\ Moussa ${ }^{2,3}$ \\ Huda Abdo Yahya Qaid' \\ 'Department of Physics and \\ Astronomy, College of Sciences, \\ King Saud University, Riyadh, Saudi \\ Arabia; ${ }^{2}$ Committee of Radiation \\ and Environmental Pollution \\ Protection (CREPP), Department \\ of Physics, College of Science, \\ Al-Imam Mohammad Ibn Saud \\ Islamic University (IMSIU), Riyadh, \\ Saudi Arabia; ${ }^{3}$ Biophysics Group, \\ Biochemistry Department, Genetic \\ Engineering and Biotechnology \\ Division, National Research Centre, \\ Giza, Egypt
}

Background: The aim of the study was to confirm the hepatotoxicity induced by small-sized gold nanoparticles (GNPs) and evaluate the role of quercetin (Qur) and arginine (Arg) against hepatotoxicity caused by GNPs.

Methods: Twenty-five healthy male Wistar-Kyoto rats were used. GNPs were administered intraperitoneally to these rats at the dose of $50 \mu \mathrm{L}$ for seven consecutive days. The role of Qur and Arg antioxidants against toxicity induced by GNPs was detected through the measurement of serum liver function and oxidative stress biomarkers in the liver tissues.

Results: Coadministration of Qur and Arg along with GNPs significantly induced dramatic alterations in the biochemical parameters. Levels of malondialdehyde, gamma-glutamyl transferase, alanine aminotransferase, alkaline phosphatase, and total protein increased significantly in the GNPs injected group than in the control group, while reduced glutathione was greatly reduced in the GNPs group than in the control group. It also significantly decreased liver enzymes and the oxidative stress, therefore improving the liver damage and hepatotoxicity induced by GNPs.

Conclusion: This study demonstrated that Qur and Arg antioxidants effectively improved the hepatic oxidative damage induced by GNPs. It also substantiates the application of Qur and Arg as protecting stand-in against GNPs' hepatotoxicity.

Keywords: antioxidants, oxidative stress, gold nanoparticles, hepatotoxicity, quercetin, arginine, rats

\section{Introduction}

Nanoparticles (NPs) have novel properties, and thus, can offer great possibilities for the environment and human diseases. Toxicological studies indicate that small-sized gold NPs (GNPs) have harmful effects on the health of humans and living species in the environment. ${ }^{1-4}$ It has been reported that exposure to smaller sized GNPs produced more inflammatory and cytotoxic reactions when compared with exposure to larger sized GNPs of same mass concentration due to their highly reactive role, surface area, and number of NPs within the biological tissues. ${ }^{1-4}$

The exposure to small-sized GNPs induces inflammatory response, venous intimal disturbance, fatty change, and Kupffer-Browicz cells' hypergenesis. The histological alterations induced in hepatocytes were mainly hydropic degeneration, cytoplasmic vacuolation, and necrosis..$^{1-3}$ Moreover, cardiac tissue damage, pneumonia, fibrosis, and chronic inflammation depend on the size and duration of exposure. ${ }^{5,6}$

The toxicity induced by GNPs was due to the changes in the physicochemical properties such as length, form, chemical make-up, combination, high specific surface area, and solubility. ${ }^{7-9}$ The pathogenic mechanisms initiated by GNPs are dominated 
by inflammation in liver, kidney, heart, and lung tissues, oxidative stress, and DNA damage.

Quercetin (Qur) is a known antioxidant and antiinflammatory/antiallergy agent, which inhibits the release of histamine and other inflammatory mediators in the body. ${ }^{10}$ In contrast, arginine (Arg) has various metabolic and immunologic effects, ${ }^{11,12}$ Arg can also act as a substance for polyamine production, which is reported to be taking part in protein production enrichment. ${ }^{13}$

It has been reported that treatment with either Qur or Arg as a protective agent may be effective against DNA, liver, and kidney damage caused by zinc oxide NPs. ${ }^{14}$ However, studies dealing with preventing the toxicity by inducing small-sized GNPs have not been recorded and acknowledged. Thus, the objective of this study is to confirm the hepatotoxicity induced by GNPs and to evaluate the function of Qur and Arg as defensive proxies against the hepatotoxicity in rats.

\section{Methods}

\section{Animals}

Twenty-five 12-week-old male Wistar-Kyoto rats weighing 220-240 g were obtained from the animal house (College of Pharmacy, KSU, Riyadh, Saudi Arabia). These rats were housed in cages under normal conditions $\left(22^{\circ} \mathrm{C} \pm 5^{\circ} \mathrm{C}\right.$ temperature, $55 \% \pm 5 \%$ humidity, 12 -h light/dark cycle) with free access to water and chow diet. All procedures related to animal care and treatments strictly adhered to the ethical procedures and policies approved by King Saud University Local Animal Care and Use Committee.

\section{GNPs and dosing}

A dose of $50 \mu \mathrm{L}(0.25 \mathrm{~mL} / \mathrm{kg} /$ day) of $10 \mathrm{~nm}$ GNPs (MKN-Au010; M K Impex Corp, MKnano, Mississauga, ON, Canada) of spherical morphology shape determined by the scanning electron microscope (SEM) was administered intraperitoneally to the rats. Each dose of Qur and Arg was $200 \mathrm{mg} / \mathrm{kg} /$ day; the doses were determined according to the previous studies. ${ }^{14,15}$

\section{Experimental design}

Rats were allowed to acclimatize for a period of 1 week; before the commencement of dose administration, rats were fasted for $24 \mathrm{~h}$ and divided into four groups: group 1 (G1), normal healthy rats $(n=10)$; group 2 (G2), GNPs intoxicated rats were left untreated $(n=5), 50 \mu \mathrm{L}$ of GNPs were administered intraperitoneally to the rats for seven consecutive days; group 3 (G3), GNPs intoxicated rats were treated with $200 \mathrm{mg} / \mathrm{kg} /$ day of Qur for seven consecutive days; and group 4 (G4), GNPs intoxicated rats were treated with $200 \mathrm{mg} / \mathrm{kg} /$ day of Arg for seven consecutive days.

\section{Blood sampling and tissue preparation}

After $24 \mathrm{~h}$ of the final dose injection, all rats were denied food for 12-14 $\mathrm{h}$ and thereafter euthanized, and blood samples from each rat were collected into sterilized tubes for serum separation. Centrifugation was carried out at 3,000 rpm for 10 min to separate the serum, and the serum was conserved at a temperature of $-80^{\circ} \mathrm{C}$ for various biochemical assessments. The midline incision technique was used to harvest and collect liver tissues; they were rinsed with freezing isosmotic saline, blended, and frozen at a temperature of $-80^{\circ} \mathrm{C}$ for biochemical tissue analyses (such as the estimations of reduced glutathione [GSH] and malondialdehyde [MDA] contents).

\section{Serum liver function markers}

A biochemical auto analyzer (model 7170; Hitachi Ltd., Tokyo, Japan) was used to determine alkaline phosphatase (ALP; Figure 1), alanine aminotransferase (ALT; Figure 2), gamma-glutamyl transferase (GGT; Figure 3), and total protein levels (Figure 4) in serum.

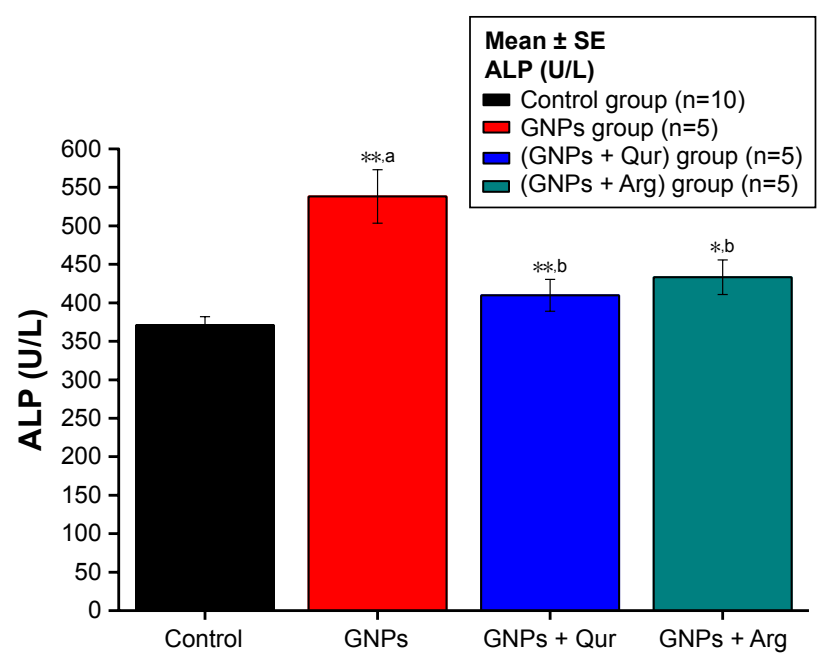

Figure I Effect of GNPs on ALP level in rats.

Notes: Image indicates a disturbance in the activity of liver ALP and a significant $(P<0.05)$ elevation by $538.17 \pm 34.7 \mathrm{I} \mathrm{U} / \mathrm{L}$ in the GNPs group as compared with $370.67 \pm 11.17 \mathrm{U} / \mathrm{L}$ in the normal control group, while the coadministration of Qur (G3) and $\operatorname{Arg}(\mathrm{G} 4)$ with GNPs significantly reduced the ALP activity to $405.33 \pm 22.69$ and $420 \pm 188.53 \mathrm{U} / \mathrm{L}$, respectively. The data of groups G3 and G4 were statistically

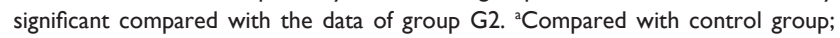
bcompared with GNPs group. $* P<0.05$; $* * P<0.01$.

Abbreviations: ALP, alkaline phosphatase; Arg, arginine; GNPs, gold nanoparticles; Qur, quercetin. 


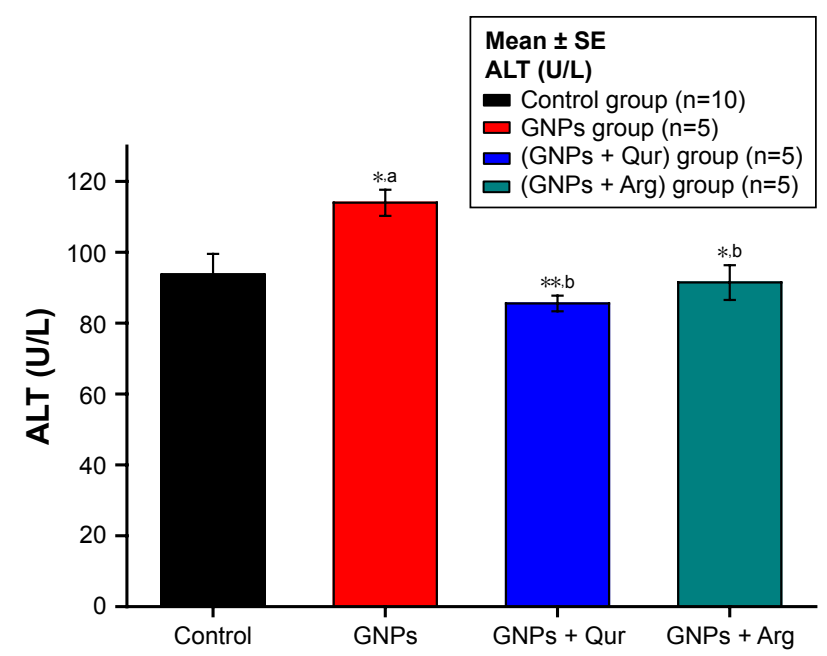

Figure 2 Effect of GNPs on ALT level in rats.

Notes: Image shows a disturbance in liver ALT and a significant $(P<0.05)$ elevation by I $14 \pm 3.7 / \mathrm{U} / \mathrm{L}$ in the GNPs group as compared with $93.70 \pm 5.88 \mathrm{U} / \mathrm{L}$ in the normal control group, while the coadministration of Qur (G3) and Arg (G4) with GNPs significantly reduced the ALT activity to $85.57 \pm 2.20$ and $91.5 \pm 4.91 \mathrm{U} / \mathrm{L}$, respectively. The data of groups G3 and G4 were statistically significant compared with the

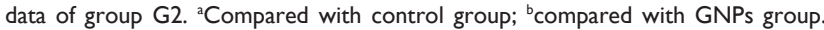
$* P<0.05 ; * * P<0.01$

Abbreviations: ALT, alanine aminotransferase; Arg, arginine; GNPs, gold nanoparticles; Qur, quercetin.

\section{Oxidative stress biomarkers}

Determination of GSH level

The measurement of GSH level $(\mu \mathrm{g} / \mathrm{mL}$; Figure 5) in liver tissues is carried out enzymatically according to the modified procedure of the previous study. ${ }^{16}$

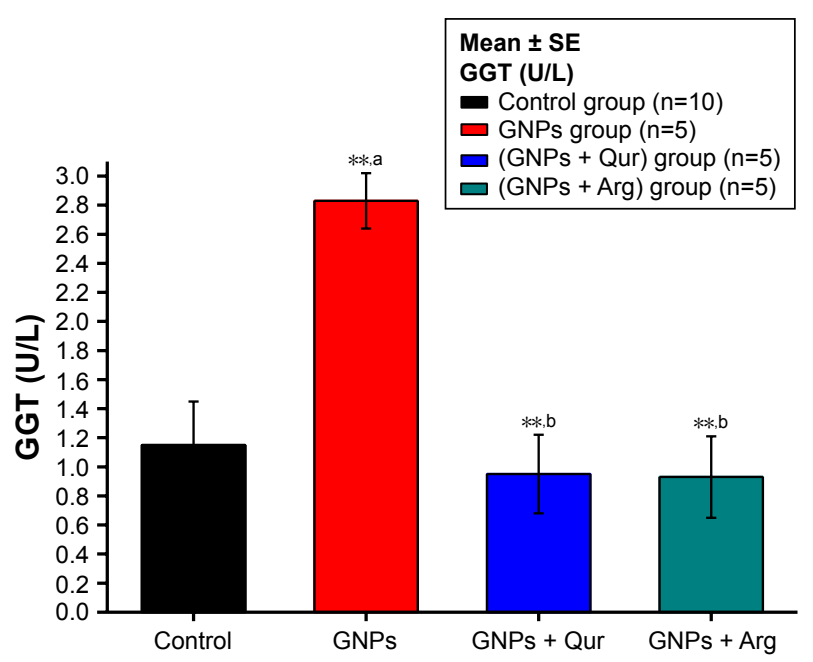

Figure 3 Effect of GNPs on GGT level in rats.

Notes: Image shows a disturbance in liver GGT and a significant $(P<0.05)$ elevation by $2.83 \pm 0.18 \mathrm{U} / \mathrm{L}$ in the GNPs group as compared with $\mathrm{I} .15 \pm 0.30 \mathrm{U} / \mathrm{L}$ in the normal control group, while the coadministration of Qur (G3) and Arg (G4) with GNPs significantly reduced the GGT activity to $0.92 \pm 0.27$ and $86.5 \pm 4.9 \mathrm{I} \mathrm{U/L}$, respectively. The data of groups G3 and G4 were statistically significant compared with the data of

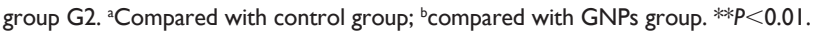
Abbreviations: Arg, arginine; GGT, gamma-glutamyl transferase; GNPs, gold nanoparticles; Qur, quercetin.

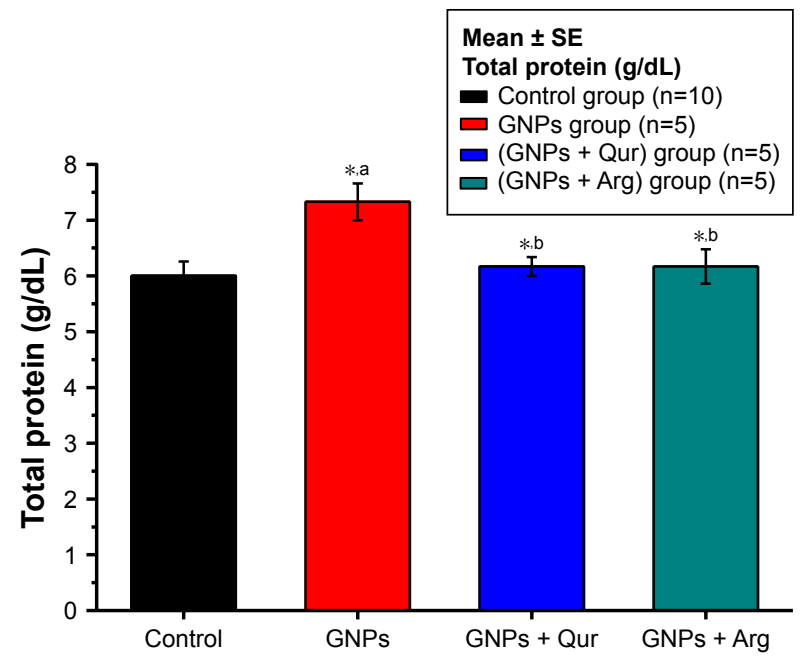

Figure 4 Effect of GNPs on total protein level in rats.

Notes: Image shows alterations in liver total protein, where a significant $(P<0.05)$ elevation by $7.33 \pm 0.33 \mathrm{~g} / \mathrm{dL}$ in the GNPs group as compared with $6.0 \pm 0.25 \mathrm{~g} / \mathrm{dL}$ in the control group was observed, while the coadministration of Qur (G3) and Arg (G4) with GNPs significantly reduced the total protein activity to $6.15 \pm 0.27$ and $6.17 \pm 4.91 \mathrm{~g} / \mathrm{dL}$, respectively. The data of groups G3 and G4 were statistically

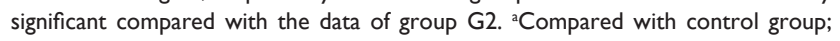
${ }^{b}$ compared with GNPs group. ${ }^{*} P<0.05$.

Abbreviations: Arg, arginine; GNPs, gold nanoparticles; Qur, quercetin.

\section{Determination of MDA}

The index of fatty acid peroxidation and the level of MDA $(\mu \mathrm{mol} / \mathrm{mL}$; Figure 6$)$ in hepatocytes of rats were determined using a spectrophotometer as defined in the previous study. ${ }^{17}$

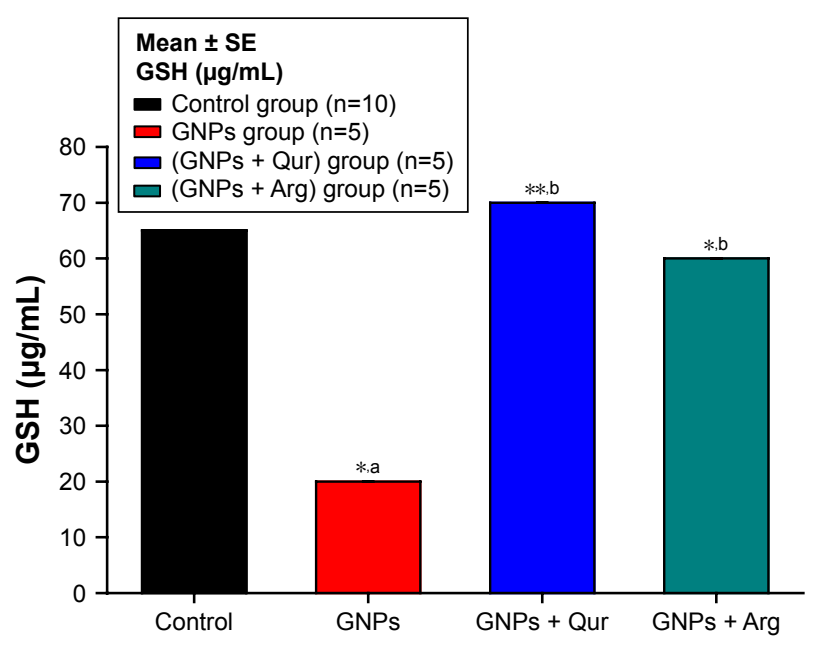

Figure 5 Effect of GNPs on liver GSH level in rats.

Notes: Image shows oxidative stress alterations in GSH liver homogenate level, where a significant $(P<0.05)$ reduction by $20 \pm 0.01 \mu \mathrm{g} / \mathrm{mL}$ in the GNPs group as compared with $65 \pm 0.01 \mu \mathrm{g} / \mathrm{mL}$ in the normal control group was observed, while the coadministration of Qur (G3) and Arg (G4) with GNPs significantly elevated the GSH to $68.12 \pm 0.27$ and $60.17 \pm 4.91 \mu \mathrm{g} / \mathrm{mL}$, respectively. The data of groups $\mathrm{G} 3$ and G4 were statistically significant compared with the data of group G2. ${ }^{\text {a Compared }}$ with control group; ${ }^{b}$ compared with GNPs group. $* P<0.05$; $* * P<0.01$.

Abbreviations: Arg, arginine; GNPs, gold nanoparticles; GSH, reduced glutathione; Qur, quercetin. 


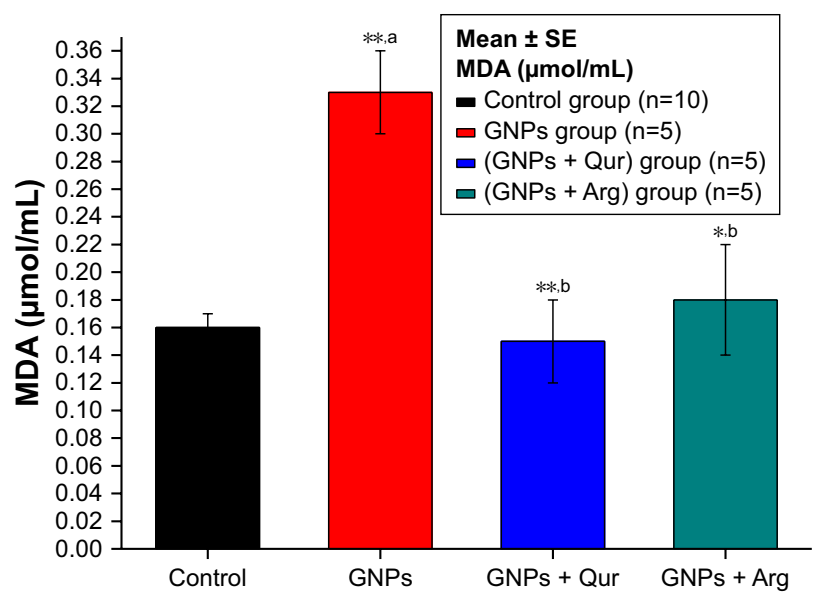

Figure 6 Effect of GNPs on liver MDA level in rats.

Notes: Image shows the level of MDA in rat liver. MDA level increased significantly $(P<0.05)$ by $0.33 \pm 0.03 \mu \mathrm{mol} / \mathrm{mL}$ in the GNPs group as compared with $0.16 \pm 0.01 \mu \mathrm{mol} / \mathrm{mL}$ in the control group, while the coadministration of Qur (G3) and $\operatorname{Arg}(\mathrm{G} 4)$ with GNPs significantly reduced the lipid peroxidation MDA activity to $0.15 \pm 0.03$ and $0.18 \pm 0.02 \mu \mathrm{mol} / \mathrm{mL}$, respectively. The data of groups $\mathrm{G} 3$ and $\mathrm{G} 4$ were statistically significant compared with the data of group G2. ${ }^{a}$ Compared with control group; 'bompared with GNPs group. ${ }^{*} P<0.05$; $* * P<0.01$.

Abbreviations: Arg, arginine; GNPs, gold nanoparticles; MDA, malondialdehyde; Qur, quercetin.

\section{Statistical analysis}

Results were expressed as mean \pm standard error. Statistical analysis was carried out by means of one-way analysis of variance (ANOVA): 1) compared with control group and $2)$ compared with GNPs group $(* P<0.05$ and $* * P<0.01)$.

\section{Results and discussion}

The present study confirmed that GNPs trigger liver tissue destruction as demonstrated by the marked rise of serum liver markers in GNPs intoxicated rats as compared with normal rats. These findings indicate that liver is the target organ for GNPs' toxicity and destruction of useful cohesion of hepatocyte membranes. Our finding was supported by the group of researchers ${ }^{18-23}$ as they stated that liver destruction could be caused by the overdose of zinc oxide NPs administration. Coadministration of Qur and Arg to GNPs rats significantly reduced all the serum liver markers $(P<0.01)$ as compared with the GNPs intoxicated rats. This may indicate that the Qur and Arg antioxidants act as protective agents against the liver dysfunction caused by hepatotoxicity of GNPs.

It has been reported that pathogenic mechanisms initiated by in vivo administration of GNPs are dominated by oxidative stress, apoptosis, and DNA damage. ${ }^{24,25}$ Thus, the protective mechanism reduces the generation of inflammatory mediators, ameliorates liver destruction, and improves organ failure. In our study, the injection of Qur or Arg immediately along with GNPs was beneficial in preventing the GNP-induced inflammatory liver injury. Our results were also consistent with those reported previously, in which Qur reduces the inflammation by inhibiting oxidative stress and cytokine production, indicating that Qur possesses anti-inflammatory effects in vivo. ${ }^{26,27}$ Moreover, Qur metabolites may act as antioxidants. ${ }^{27}$ In contrast, in other studies, it was found that Arg supplementation protects oxidative damage. ${ }^{18,19}$ The defense by Qur in contrast to the creation of oxidative DNA destruction caused by $\mathrm{H}_{2} \mathrm{O}_{2}$ was observed in vitro. ${ }^{20}$ Arg mitigates oxidative stress in the hepatocytes and brain tissues and has antioxidant activities, as well as reactive oxygen species (ROS)-scavenging properties. ${ }^{21}$ Coadministration with Arg was able to inhibit DNA fragmentation and increased wound DNA synthesis. ${ }^{22,23}$

It has been reported that $1.4 \mathrm{~nm}$ NPs react with DNA and caused strong toxicity near human tumors, since it is commonly reported that DNA double-strand disruptions may lead to cancer. ${ }^{1-3}$ NPs induced oxidative stress, and one of the likely means, which induce DNA destruction, may be fatty acid peroxidation and oxidative stress. ${ }^{26}$

ROS reacts with DNA particle leading to the destruction of purine and pyrimidine bases as well as DNA support. ${ }^{26} \mathrm{MDA}$ is one of the main products of fatty acid peroxidation. It is a mutagenic and also a carcinogenic substance. It combines with DNA-forming compounds such as deoxyguanosine, deoxyadenosine, and deoxycytidine. ${ }^{27,28}$ DNA damage may trigger signal transduction pathways, giving rise to apoptosis or causing cell death. ${ }^{29}$ Coadministration of Qur and Arg to GNPs intoxicated rats effectively protected liver from lipid peroxidation and inflammatory damage. Our data were also consistent with the previously published study. ${ }^{29}$ Qur possesses anti-inflammatory, antioxidant, hepatoprotective, and anticarcinogenic activities. ${ }^{30}$

\section{Conclusion}

This study highlights the hepatotoxic effects induced by intraperitoneal administration of GNPs, which was confirmed by a significant increase in liver function markers, such as ALP, ALT, GGT, and total protein. In addition there was a significant elevation in the tissue lipid peroxidation biomarker MDA and a significant reduction in the oxidative stress biomarker GSH level. The treatment with either Qur or Arg successively alleviated ALP, ALT, GGT, total protein and MDA. While GSH increased, this in turn effectively ameliorated the lipid peroxidation and inflammatory liver damage induced in GNPs intoxicated rats. Our data demonstrated that Qur and Arg are highly potent antioxidants that have the ability to protect hepatocytes from damage, which is produced by oxidative stress and the associated vascular problems caused by the generation of GNPs, from the production of ROS. More research is required to assess the synergistic combination of Qur and Arg, which might be useful to completely inhibit the hepatotoxicity induced by GNPs. 


\section{Acknowledgment}

The authors would like to extend their sincere appreciation to the Deanship of Scientific Research at King Saud University for its funding of this research through the Research Group Project No RGP-285.

\section{Disclosure}

The authors report no conflicts of interest in this work.

\section{References}

1. Abdelhalim MA, Jarrar BM. Histological alterations in the liver of rats induced by different gold nanoparticles size, dose and exposure duration. J Nanobiotechnology. 2012;10:5.

2. Abdelhalim MA, Jarrar BM. Renal tissue alterations were size-dependent with smaller ones induced more effects and related with time exposure of gold nanoparticles. Lipids Health Dis. 2011;10:163.

3. Abdelhalim MA, Jarrar BM. Gold nanoparticles induced cloudy swelling to hydropic degeneration, cytoplasmic hyaline vacuolation, polymorphism, binucleation, karyopyknosis, karyolysis, karyorrhexis and necrosis in the liver. Lipids Health Dis. 2011;10:166.

4. Nel A, Xia T, Madler L, Li N. Toxic potential of materials at the nano level. Science. 2006;311(5761):622-627.

5. Abdelhalim MA. Exposure to gold nanoparticles produces cardiac tissue damage that depends on the size and duration of exposure. Lipids Health Dis. 2011;10:205.

6. Abdelhalim MA. Gold nanoparticles administration induces disarray of heart muscle, hemorrhagic, chronic inflammatory cells infiltrated by small lymphocytes, cytoplasmic vacuolization and congested and dilated blood vessels. Lipids Health Dis. 2011;10:233.

7. Lovern SB, Klaper R. Daphnia magna mortality when exposed to titanium dioxide and fullerene (C60) nanoparticles. Environ Toxicol Chem. 2006;25(4):1132-1137.

8. Franklin NM, Rogers NJ, Apte SC, Batley GE, Gadd GE, Casey PS. Comparative toxicity of nanoparticulate $\mathrm{ZnO}$, bulk $\mathrm{ZnO}$, and $\mathrm{ZnCl} 2$ to a freshwater microalga (Pseudokirchneriella subcapitata): the importance of particle solubility. Environ Sci Technol.2007;4124(24): 8484-8490.

9. Wang Z, Zhou J, Fan J, et al. Effect of rapamycin alone and in combination with sorafenib in an orthotopic model of human hepatocellular carcinoma. Clin Cancer Res. 2008;14(16):5124-5130.

10. Jung WJ, Sung MK. Effects of major dietary antioxidant on inflammatory markers of RAW 264.7 macrophages. Biofactors. 2004;21(1-4): 113-117.

11. Huang CC, Tsai SC, Lin WT. Potential ergogenic effects of Arg against oxidative and inflammatory stress induced by acute exercise in aging rats. Exp Gerontol. 2008;43(6):571-577.

12. Ivanov V, Cha J, Ivanova S, et al. Essential nutrients suppress inflammation by modulating key inflammatory gene expression. Int $\mathrm{J} \mathrm{Mol} \mathrm{Med}$. 2008;22(6):731-741.

13. Moinard C, Cynober L, de Bandt JP. Polyamines: metabolism and implications in human diseases. Clin Nutr. 2005;24(2):184-197.
14. Faddah LM, Baky NA, Al-Rasheed NM, Al-Rasheed NM, Fatani AJ, Atteya M. Role of quercetin and arginine in ameliorating nano zinc oxide-induced nephrotoxicity in rats. BMC Complement Altern Med. 2012;12(1):1062.

15. Baky NA, Faddah LM, Al-Rasheed NM, Al-Rasheed NM, Shebali W. Role of quercetin and L-arginine in alleviating zinc oxide nanoparticle hepatotoxicity in rats. Chiang Mai J Sci. 2013;40(4):577-592.

16. Griffith OW. Determination of glutathione and glutathione disulfide using glutathione reductase and 2-vinylpyridine. Anal Biochem. 1980; 106(1):207-212.

17. Utley HG, Bernheim F, Hochstein P. Effect of sulfhydryl reagents on peroxidation in microsomes. Arch Biochem Biophys. 1967;118(1): 29-32.

18. Gurr JR, Wang AS, Chen CH, Jan KY. Ultrafine titanium dioxide particles in the absence of photoactivation can induce oxidative damage to human bronchial epithelial cells. Toxicology. 2005;213(1-2): $66-73$.

19. Collins AR, Dusinska M, Gedik CM, Stětina R. Oxidative damage to DNA: do we have a reliable biomarker? Environ Health Perspect. 1996; 104(suppl 3):465.

20. Wilms LC, Hollman PC, Boots AW, Kleinjans JC. Protection by qur and Qur-rich fruit juice against induction of oxidative DNA damage and formation of BPDE-DNA adducts in human lymphocytes. Mutat Res. 2005;582:155-162.

21. Lass A, Suessenbacher A, Wolkart G, Mayer B, Brunner F. Functional and analytical evidence for scavenging of oxygen radicals by Arg. Mol Pharmacol. 2002;61:1081-1088.

22. Piacenza L, Peluffo G, Radi R. Arg-dependent suppression of apoptosis in trypanosoma cruzi: contribution of the nitric oxide and polyamine path ways. Proc Natl Acad Sci U S A. 2001;98(13):7301-7306.

23. Zhang XJ, Chinkes DL, Wu Z, Herndon DN. Enternal Arg supplementation stimulates DNA synthesis in skin donor wound. Clin Nutr. 2011; 30(3):391-396.

24. Borm PJ, Robbins D, Haubold S, et al. The potential risks of nanomaterials: a review carried out for ECETOC. Part Fibre Toxicol. 2006;3:11.

25. Lu S, Duffin R, Poland C, Daly P, Murphy F, Drost E. Efficacy of simple short-term in vitro assays for predicting the potential of metal oxide nanoparticles to cause pulmonary inflammation. Environ Health Perspect. 2009;117(2):241-247.

26. Xiong D, Fang T, Yu L, Sima X, Zhu W. Effects of nano-scale TiO2, $\mathrm{ZnO}$ and their bulk counterparts on zebrafish: acute toxicity, oxidative stress and oxidative damage. Sci Total Environ. 2011;409(8): 1444-1452.

27. Marnett LJ. Oxy radicals, lipid peroxidation and DNA damage Toxicology. 2002;181-182:219-222.

28. Niedernhofer LJ, Daniels JS, Rouzer CA, Greene RE, Marnett LJ. Malondialdehyde, a product of lipid peroxidation, is mutagenic in human cells. J Biol Chem. 2003;278(33):31426-31433.

29. Sharma V, Shukla RK, Saxena N, Parmar D, Das M, Dhawan A. DNA damaging potential of zinc oxide nanoparticles in human epidermal cells. Toxicol Lett. 2009;185(3):211-218.

30. Middleton E Jr, Kandaswami C, Theoharides TC. The effects of plant flavonoids on mammalian cells: implications for inflammation, heart disease, and cancer. Pharmacol Rev. 2000;52(4):673-751.
International Journal of Nanomedicine

\section{Publish your work in this journal}

The International Journal of Nanomedicine is an international, peerreviewed journal focusing on the application of nanotechnology in diagnostics, therapeutics, and drug delivery systems throughou the biomedical field. This journal is indexed on PubMed Central, MedLine, CAS, SciSearch ${ }^{\circledR}$, Current Contents ${ }^{\circledR} /$ Clinical Medicine,

\section{Dovepress}

Journal Citation Reports/Science Edition, EMBase, Scopus and the Elsevier Bibliographic databases. The manuscript management system is completely online and includes a very quick and fair peer-review system, which is all easy to use. Visit http://www.dovepress.com/ testimonials.php to read real quotes from published authors. 